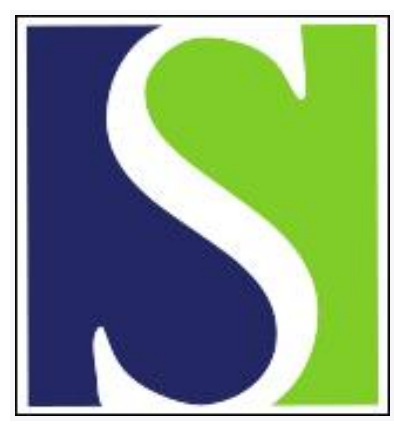

Scand J Work Environ Health 1998;24(5):344-350

https://doi.org/10.5271/sjweh.354

Issue date: Oct 1998

\title{
Job strain and time to pregnancy
}

by Hjollund NHI, Kold Jensen T, Bonde JPE, Henriksen TB, Kolstad HA, Andersson A-M, Ernst E, Giwercman A, Skakkebæk NE, Olsen J

Key terms: fecundability; fertility; occupation; prospective data; reproduction; stress

This article in PubMed: www.ncbi.nlm.nih.gov/pubmed/9869305

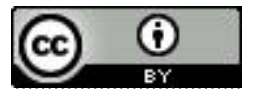




\title{
Job strain and time to pregnancy
}

\author{
by Niels Henrik I Hjollund, MD, ${ }^{1}$ Tina Kold Jensen, PhD, ${ }^{2}$ Jens Peter E Bonde, PhD, ${ }^{1}$ \\ Tine $B$ Henriksen, PhD, ${ }^{3}$ Henrik A Kolstad, PhD, ${ }^{1}$ Anna-Maria Andersson, PhD, ${ }^{2}$ Erik Ernst, PhD, ${ }^{4}$ \\ Aleksander Giwercman, DrMedSc, ${ }^{2}$ Niels Erik Skakkebæk, DrMedSc, ${ }^{2}$ Jorn Olsen, PhD ${ }^{5}$
}

\begin{abstract}
Hjollund NHI, Kold Jensen T, Bonde JPE, Henriksen TB, Kolstad HA, Andersson A-M, Ernst E, Giwercman A, Skakkebæk NE, Olsen J. Job strain and time to pregnancy. Scand J Work Environ Health 1998;24(5):344-350.

Objectives The association between fertility and job strain defined as high job demands and low job control has not previously been studied. A follow-up study was conducted with prospective collection of information on job strain among women, achievement of pregnancy, and potential confounding variables.

Methods A total of 297 Danish couples without previous reproductive experience was followed for a maximum of 6 menstrual cycles from termination of birth control until pregnancy. Job demand and job control were measured by a questionnaire developed by Karasek and his co-workers.

Results The odds ratio and $95 \%$ confidence interval $(95 \% \mathrm{CI})$ for conception per menstrual cycle for women with high job strain was $0.9(95 \% \mathrm{Cl} 0.5-1.5)$ when compared with that of women in low-strain jobs. Only in secondary analyses restricted to couples with no suspected competitive causes of reduced fertility was a statistically significant reduced odds found for women with high-strain jobs compared with all other jobs.

Conclusions The main finding of this study did not corroborate a hypothesis of a substantial detrimental effect of job strain on fecundability.
\end{abstract}

Key terms fecundability, fertility, occupation, prospective data, reproduction, stress.

The impact of psychosocial work conditions on somatic diseases has been studied since the beginning of the 1970 s, and much inspiration has been provided by the job decision-job demand model developed by Karasek $\&$ Theorell in the 1980 s (1). In the field of human reproduction this model has been used in studies of various end points, such as menstrual cycle pattern, spontaneous abortion, birthweight, and gestational age (2-6).

So far no studies have dealt with job decision and demand in relation to fecundity. Animal studies and physiological considerations have suggested that exposure to psychological stressors may be related to functional changes in the female reproductive system at levels such as the autonomic nerve system, the endocrine system, and the immune system ( $7-11$ ). Furthermore, stressors may induce behavioral changes in sexual activity.

The objective of this study was to estimate whether job strain influences couple fecundability, defined as the probability of conception in a menstrual cycle with no use of contraception. Information on both exposure and outcome was collected prospectively during a follow-up period of up to 6 menstrual cycles.

\section{Subjects and methods}

From 1992 to 1994,430 couples were recruited after a nationwide mailing of a personal letter to 52255 trade union members (metal workers, office and commercial workers, nurses and day-care workers) who were 20 35 years of age, were living with a partner, and were childless. Only couples without earlier reproductive experience who intended to discontinue contraception in order to conceive a child were eligible for enrollment. We estimate that $10-20 \%$ of the eligible couples

1 Department of Occupational Medicine, Aarhus University Hospital, Aarhus, Denmark.

2 Department of Growth and Reproduction, Rigshospitalet, Copenhagen, Denmark.

3 Perinatal Epidemiological Research Unit, Department of Gynaecology and Obstetrics, Aarhus University Hospital, Aarhus, Denmark.

4 Reproductive Toxicology Unit, Institute of Neurobiology, Aarhus University, Aarhus, Denmark.

5 Danish Epidemiology Science Center, Aarhus University, Aarhus, Denmark.

Reprint requests to: Dr Niels Henrik I Hjollund, Department of Occupational Medicine, Aarhus University Hospital, Noerrebrogade 44, DK-8000 Aarhus C, Denmark. [E-mail: akh.gp22s.akamkhh1@aaa.dk] 
participated. A detailed description of the cohort and design has been given elsewhere (12).

The couples were enrolled into the study when they discontinued birth control, and they were followed up to 6 menstrual cycles or until a pregnancy was recognized by a general practitioner. At enrollment both partners filled out a questionnaire on job strain, psychological distress, and demographic, medical, reproductive, occupational and life-style factors. On the 21 st day of each menstrual cycle during the follow-up, the couples completed questionnaires on changes in occupational exposures and life-style factors, and the woman recorded vaginal bleeding and sexual intercourse in a diary.

First-morning urine samples from days 1 to 10 in each menstrual cycle, starting the first morning with menstrual bleeding, were stored in a freezer for the determination of human choriongonadotropic hormone, which indicates early embryonic loss (12). Information on spontaneous abortion in clinically recognized pregnancies was collected by postal questionnaire or interview 1 year after the 6-cycle follow-up was terminated. A $100 \%$ response-rate was achieved.

Only cycles in which the female partner was employed for at least 25 hours a week were included in the analyses (table 1). Furthermore, women who were pregnant when filling out the entry questionnaire or who had left any job-strain items missing were excluded. No cycles with reported sexual abstinence from day 11 to 20 in the menstrual cycle resulted in a pregnancy. These cycles were also excluded. Altogether 297 couples contributing 1159 menstrual cycles were included in the analysis.

Psychological job strain was assessed according to the questionnaire developed by Karasek and his colleagues $(1,13)$. The concept includes at least 2 dimensions, job demands and job control (24 items). Furthermore information on support from the subject's supervisor and coworkers was requested (12 items). On the basis of the information collected at the start of the follow-up, the couples were categorized into 4 levels according to the women's scores on the 2 dimensions. The couples were also categorized according to the women's scores for the combined dimensions (job strain). Both job demand and job control were divided according to the median score values, the result being 4 different types of jobs, namely, low-strain jobs (low demand and high control score), active jobs (high demand and high control), passive jobs (low demand and low control), and high-strain jobs (high demand and low control). Finally, other indicators of job stressors were examined, including shift work and knowledge about work schedule in advance. Information on changes in female job strain during the follow-up was collected on the 21 st day of each menstrual cycle. The participants were asked to rate the changes in female job demand and job control as more, the same, or less.

The unit of observation in the analyses was a menstrual cycle, and each cycle was numbered according to the number of menstrual cycles since the discontinuation of contraception. The association between job strain and fecundability was estimated by a logistic regression model controlling for confounding factors $(14,15)$. This model provides a fecundability odds ratio (OR), which is the estimated odds of conception in a menstrual cycle for the exposed group divided by the corresponding odds for the unexposed group. Menstrual cycle numbers were entered as dummy variables to adjust for changes in base-line fecundability with an increasing number of cycles of trying to conceive. Potential confounding variables were selected according to their biological relevance irrespective of the association with exposure in the present data set. The following variables were included: center (east, west), recruitment group (metal workers, nurses, office workers, day-care workers), further education of the woman (yes, no), age of the woman $(\leq 24,25-29, \geq 30$ years), body mass index of the woman $(\leq 19,20-24, \geq 25$ $\mathrm{kg} / \mathrm{m}^{2}$ ), regular use of intrauterine devices or oral contraceptives the year before enrollment (yes, no), self-reported reproductive disease of either the man or the woman (yes, no), sperm density ( $\leq 20, \geq 21 \cdot 10^{6}$ spermatozoa/ $\mathrm{ml}$ ), female cigarette smoking (yes, no), caffeine intake $(\leq 149, \geq 150 \mathrm{mg}$ caffeine/day) and weekly alcohol consumption (yes, no). Menstrual cycle length and

Table 1. Identification of the cycles included in the analyses, showing the reasons for exclusion and the final number of pregnancy attempts accepted.

\begin{tabular}{|c|c|c|c|c|c|c|c|c|}
\hline & \multirow[t]{2}{*}{ Couples } & \multicolumn{6}{|c|}{ Cycle } & \multirow[t]{2}{*}{ Total } \\
\hline & & 1 & 2 & 3 & 4 & 5 & 6 & \\
\hline Pregnancy attempts under observation & 430 & 430 & 358 & 287 & 241 & 187 & 158 & 1661 \\
\hline 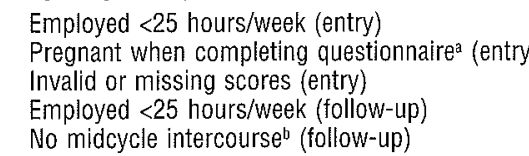 & $\begin{array}{r}86 \\
29 \\
18 \\
.\end{array}$ & $\begin{array}{r}86 \\
29 \\
18 \\
1 \\
5\end{array}$ & $\begin{array}{r}70 \\
13 \\
13 \\
3 \\
4\end{array}$ & $\begin{array}{r}57 \\
6 \\
10 \\
2 \\
14\end{array}$ & $\begin{array}{r}48 \\
3 \\
9 \\
6 \\
4\end{array}$ & $\begin{array}{r}39 \\
- \\
8 \\
5 \\
5\end{array}$ & $\begin{array}{r}35 \\
- \\
7 \\
2 \\
-\end{array}$ & $\begin{array}{r}335 \\
51 \\
65 \\
19 \\
32\end{array}$ \\
\hline Pregnancy attempts included in analyses & 297 & 291 & 255 & 198 & 171 & 130 & 114 & 1159 \\
\hline
\end{tabular}

a Filled out entry questionnaire after 28th day in entry cycle which resulted in pregnancy.

brom 20 to 11 days prior to expected onset of the next menstrual bleeding. 
frequency of sexual intercourse may be determinants of fertility, as well as intermediate steps in a causal chain between job strain and fertility. Models both with and without these factors were analyzed [categories: menstrual cycle length ( $\leq 34, \geq 35$ days), frequency of sexual intercourse per week $(<1, \geq 1)]$. Possible interactions between exposure and confounders were evaluated by stratified analyses.

\section{Results}

During the follow-up 170 women had a clinically detected pregnancy (table 2). The median score on the job-demand and job-control axes were 30 (range 12-46) and 72 (range $28-94$ ), respectively. The distribution of various job descriptors and potential confounding variables are given in an appendix with the median position of each stratum on the job strain axes. The association between fecundability and psychosocial factors related to the job are shown in table 3 . The crude odds ratios were statistically insignificant, and adjustment for potential confounding variables provided unchanged estimates (data not shown).

The crude fecundability was $11.8 \%$ for the women in high-strain jobs compared with $17.1 \%, 15.1 \%$, and $13.0 \%$ for the women in passive jobs, active jobs, and low-strain jobs, respectively. The fecundability odds ratio for the women in high-strain jobs versus women in low-strain jobs was 0.9 [95\% confidence interval $(95 \%$ CI) $0.5-1.5]$ (table 4). The estimates were robust to adjustment for potential confounding variables (table 4). Compared with that of all other jobs, the adjusted OR was 0.8 (95\% CI 0.5-1.2) for the high-strain jobs. When a more restrictive definition was used for high-strain job (job control score below lower tertile and job demand score above upper tertile), the corresponding OR was 0.7 (95\% CI $0.4-1.3)$. Stratification by mean menstrual cycle length, frequency of sexual intercourse, and the other potential confounding variables revealed similar estimates.

When couples with reduced fecundity suspected a priori were excluded from the analysis (male or female reproductive disease), sperm count $<20 \cdot 10^{6} / \mathrm{ml}$, unsafe contraceptive method in the year before enrollment, $<1$ weekly sexual intercourse), a significantly reduced fecundability among the women in high-strain jobs was found [OR for high-strain jobs in comparison with lowstrain jobs being 0.4 (95\% CI $0.2-1.0)$ and OR for the tertile of women with the highest job strain compared with all other women also being 0.4 (95\% Cl $0.2-0.9$ ), $\mathrm{N}=415$ cycles].

During the follow-up $15 \%$ and $9 \%$ of the women reported changes in job demands and job control, respectively, and the changes were mostly towards higher job control and higher job demands (table 2). Eliminating this source of misclassification in exposure by censoring cycles with reported change in job strain provided results similar to the ones obtained in the analyses based on the entire number of cycles ( $N=898$, data not shown).

The proportion of pregnancies terminated by pregnancy loss (subclinical early embryonal loss or spontaneous abortion of a clinically recognized pregnancy) was $29.5 \%$. The odds ratio for pregnancies conceived by women in a high-strain job was $0.9(95 \%$ CI $0.4-2.2)$ when compared with all other pregnancies.

\section{Discussion}

The main finding of this study did not corroborate a hypothesis of a substantial detrimental effect on fecundability among women in high-strain jobs. When we restricted the cohort to couples with no other suspected causes of reduced fertility, a $60 \%$ reduction of the odds was seen. However, this result was data-driven and should be confirmed by others.

Table 2. Characteristics of the menstrual cycles of the 297 participating couples.

\begin{tabular}{|c|c|c|c|c|c|c|c|}
\hline & \multicolumn{6}{|c|}{ Cycle } & \multirow[t]{2}{*}{ Total } \\
\hline & 1 & 2 & 3 & 4 & 5 & 6 & \\
\hline \multicolumn{7}{|l|}{ Termination of follow-up } & 1159 \\
\hline $\begin{array}{l}\text { Pregnancy } \\
\text { Stop attempt after completing cycle }\end{array}$ & $\begin{array}{r}33 \\
2\end{array}$ & $\begin{array}{r}42 \\
5\end{array}$ & $\begin{array}{r}28 \\
5\end{array}$ & $\begin{array}{r}32 \\
7\end{array}$ & $\begin{array}{r}19 \\
3\end{array}$ & $\begin{array}{r}13 \\
2\end{array}$ & $\begin{array}{r}167^{3} \\
24\end{array}$ \\
\hline \multicolumn{8}{|c|}{ Change in job control (from previous cycle) $(\%)$} \\
\hline $\begin{array}{l}\text { Cycles with higher score } \\
\text { Cycles with lower score }\end{array}$ & $\begin{array}{l}8 \\
1\end{array}$ & $\begin{array}{l}7 \\
1\end{array}$ & $\begin{array}{l}8 \\
0\end{array}$ & $\begin{array}{l}9 \\
4\end{array}$ & $\begin{array}{l}7 \\
4\end{array}$ & $\begin{array}{l}3 \\
3\end{array}$ & $\begin{array}{l}7 \\
2\end{array}$ \\
\hline \multicolumn{8}{|c|}{ Change in job demands (from previous cycle) $(\%)$} \\
\hline $\begin{array}{l}\text { Cycles with higher score } \\
\text { Cycles with lower score }\end{array}$ & $\begin{array}{r}14 \\
0\end{array}$ & $\begin{array}{r}13 \\
2\end{array}$ & $\begin{array}{r}18 \\
0\end{array}$ & $\begin{array}{r}17 \\
0\end{array}$ & $\begin{array}{r}14 \\
0\end{array}$ & $\begin{array}{r}15 \\
0\end{array}$ & $\begin{array}{r}15 \\
0\end{array}$ \\
\hline
\end{tabular}

a An additional 3 women became pregnant in a period of working less than 25 hours/week and were excluded from the cycle-specific analyses. 
Several precautions were taken to eliminate information bias and the differential selection of subfertile couples into the study. Couples with a priori knowledge about their own reproductive capability were not eligible, and we excluded couples who completed the questionnaire after a pregnancy was detected or when they might have had some knowledge that a pregnancy was underway. Thus information on job-strain measures was collected prospectively in relation to the outcome.

Planning bias may arise if the use of unsafe birth control methods is associated with the exposure of interest (16). If women in high-strain jobs use less efficient birth control methods, the most fertile of these couples may conceive unintentionally and thus never become eligible for this study. Planning bias cannot be completely ruled out without knowledge of exposure among nonplanners, but, if birth control methods vary considerably, this variation would probably be reflected among the enrolled couples as well. Among the high-strain women, $66.7 \%$ used oral contraceptives or intrauterine devices compared with $66.2 \%$ of the women in other jobs. It is therefore not likely that this potential bias had a major influence on our results.

The way the couples interpreted and responded to our psychosocial questionnaires may have been influenced by their educational and social background, and an association between, for example, educational background and job strain was found. However, the same issues were not statistically significantly associated with fecundability, and adjustment for education, trade union, or other a priori selected confounding variables failed to change the estimates substantially.

This study was part of a larger study of a wide range of environmental and biological determinants of fertility, and it is likely that the demanding protocol has conferred a differential selection of couples according to their job strain. However, the median values of the job demand and job control scores of 30 and 72 , respectively, found in our study are comparable with the findings in a cohort of pregnant women attending a Danish antenatal clinic at 16 gestational weeks (29 and 70, respectively ( 5 , personal communication). The findings of our study may thus apply to job strain experienced by representative samples of women in the general population. However, it is not justified to generalize the results to populations with extreme levels of job strain.

Possible adverse effects of job strain have primarily been studied in the field of cardiovascular diseases. A simplified model suggests that job stressors result in chronic distress, which through physiological or behavioral changes may lead to heart disease (17). In the present study both job demands and job control were related to the level of distress measured by the general health questionnaire (GHQ). Previous analyses of our cohort revealed reduced fertility among the women with
Table 3. Work-related psychosocial factors - crude $^{a}$ fecundability odds ratios (OR) and $95 \%$ confidence intervals $(95 \% \mathrm{Cl})$.

\begin{tabular}{|c|c|c|c|}
\hline $\begin{array}{l}\text { Work-related } \\
\text { psychosoical factor }\end{array}$ & $\begin{array}{l}\text { Cycles } \\
(\mathrm{N})\end{array}$ & $\mathrm{OR}$ & $95 \% \mathrm{Cl}$ \\
\hline \multicolumn{4}{|l|}{ High job control (percentiles) } \\
\hline $\begin{array}{l}0-25 \\
26-50 \\
51-75 \\
76-100\end{array}$ & $\begin{array}{l}322 \\
311 \\
308 \\
218\end{array}$ & $\begin{array}{c}0.8 \\
1.3 \\
1.0 \\
\text { Reference }\end{array}$ & $\begin{array}{l}0.5-1.4 \\
0.8-2.1 \\
0.6-1.6\end{array}$ \\
\hline \multicolumn{4}{|l|}{ High job demands (percentiles) } \\
\hline $\begin{array}{l}0-25 \\
26-50 \\
51-75 \\
76-100\end{array}$ & $\begin{array}{l}313 \\
293 \\
300 \\
253\end{array}$ & $\begin{array}{c}\text { Reference } \\
1.3 \\
1.0 \\
1.0\end{array}$ & $\begin{array}{l}0.8-2.0 \\
0.6-1.5 \\
0.6-1.6\end{array}$ \\
\hline \multicolumn{4}{|l|}{ Social support (percentiles) } \\
\hline $\begin{array}{l}0-50 \\
51-100\end{array}$ & $\begin{array}{l}537 \\
622\end{array}$ & $\begin{array}{c}1.3 \\
\text { Reference }\end{array}$ & $0.9-1.8$ \\
\hline \multicolumn{4}{|l|}{ Hours at work per week (hours) } \\
\hline $\begin{array}{l}25-39 \\
\geq 40\end{array}$ & $\begin{array}{l}904 \\
255\end{array}$ & $\begin{array}{c}\text { Reference } \\
1.1\end{array}$ & $0.8-1.7$ \\
\hline \multicolumn{4}{|l|}{ Regular workhours } \\
\hline $\begin{array}{l}\text { Yes } \\
\text { No }\end{array}$ & $\begin{array}{l}733 \\
423\end{array}$ & $\begin{array}{l}\text { Reference } \\
\quad 1.2\end{array}$ & $0.8-1.6$ \\
\hline \multicolumn{4}{|l|}{ Work shift } \\
\hline $\begin{array}{l}\text { Only daytime } \\
\text { Evening and daytime } \\
\text { Night work }(\geq 25 \%)\end{array}$ & $\begin{array}{l}860 \\
139 \\
157\end{array}$ & $\begin{array}{c}\text { Reference } \\
1.5 \\
1.2\end{array}$ & $\begin{array}{l}0.9-2.4 \\
0.7-1.9\end{array}$ \\
\hline \multicolumn{4}{|l|}{$\begin{array}{l}\text { Knowledge about work schedule } \\
\text { a week in advance }\end{array}$} \\
\hline $\begin{array}{l}\text { Yes, usually } \\
\text { No, often changes or overtime }\end{array}$ & $\begin{array}{l}963 \\
130\end{array}$ & $\begin{array}{l}\text { Reference } \\
\quad 0.6\end{array}$ & $0.3^{\circ}-1.1$ \\
\hline
\end{tabular}

Table 4. Psychosocial job-strain measures - crude and adjusted fecundability ratios (OR) and $95 \%$ confidence intervals $(95 \% \mathrm{Cl})$.

\begin{tabular}{|c|c|c|c|c|c|}
\hline $\begin{array}{l}\text { Psychosocial } \\
\text { job-strain } \\
\text { measure }\end{array}$ & $\begin{array}{l}\text { Cycles } \\
(\mathrm{N})\end{array}$ & $\begin{array}{c}\text { Crude }^{\mathrm{a}} \\
\text { OR }\end{array}$ & $\begin{array}{c}95 \% \mathrm{Cl} \\
\text { of the } \\
\text { crude OR }\end{array}$ & $\begin{array}{l}\text { Adjusted } \\
\text { OR }\end{array}$ & $\begin{array}{l}95 \% \mathrm{Cl} \\
\text { of the ad- } \\
\text { justed OR }\end{array}$ \\
\hline \multicolumn{6}{|c|}{ Categorized into 4 levels by median values } \\
\hline $\begin{array}{l}\text { High-strain jobc } \\
\text { Passive job } \\
\text { Active job } \\
\text { Low-strain job }\end{array}$ & $\begin{array}{l}288 \\
345 \\
265 \\
261\end{array}$ & $\begin{array}{c}0.9 \\
1.4 \\
1.2 \\
\text { Reference }\end{array}$ & $\begin{array}{l}0.5-1.5 \\
0.9-2.2 \\
0.7-1.9\end{array}$ & $\begin{array}{c}0.9 \\
1.4 \\
1.0 \\
\text { Reference }\end{array}$ & $\begin{array}{c}0.5-1.5 \\
0.9-2.3 \\
0.6-1.8 \\
.\end{array}$ \\
\hline \multicolumn{6}{|c|}{ Categorized into 2 levels by median values } \\
\hline $\begin{array}{l}\text { High-strain jobc } \\
\text { All other jobs }\end{array}$ & $\begin{array}{l}288 \\
871\end{array}$ & $\begin{array}{c}0.7 \\
\text { Reference }\end{array}$ & $0.5-1.1$ & $\begin{array}{c}0.8 \\
\text { Reference }\end{array}$ & $0.5-1.2$ \\
\hline \multicolumn{6}{|c|}{ Categorized into 2 levels by tertile values } \\
\hline $\begin{array}{l}\text { High-strain jobs } \\
\text { All other jobs }\end{array}$ & $\begin{array}{l}s^{d} 113 \\
1046\end{array}$ & $\begin{array}{c}0.7 \\
\text { Reference }\end{array}$ & $0.4-1.4$ & $\begin{array}{c}0.7 \\
\text { Reference }\end{array}$ & $0.4-1.3$ \\
\hline
\end{tabular}

adjusted for cycle number.

b Adjusted for cycle number, center, recruitment group, education, age of the woman, regular use of intrauterine devices or oral contraceptives the year prior to enrollment, self-reported reproduction-related disease of the man or woman, oligospermia, body mass index of the woman, cigarette smoking, caffeine, and alcohol consumption.

- Job control below median value, job demand above median value.

d Job control below lower tertile, job demand above upper tertile.

a high level of distress, most pronounced if the menstrual cycles exceeded 30 days (unpublished observations). Adding the GHQ score of the women to our model of job strain and fertility failed to change our estimates. 
Furthermore, no indication of a mediation through changes in sexual behavior (reduced frequency of unprotected intercourse) was found.

\section{Acknowledgments}

This study was mainly supported by a grant from the Aarhus University Research Foundation (J.n. 1994$7430-1$ ), but additional support was also provided by the Danish Medical Research Council (J.nr. 12-20421), the Danish Medical Heath Insurance Foundation (J.nr. 11/236-93 and J.nr. 11/243-91), and the Institute of Experimental Clinical Research, Aarhus University. The activities of the Danish Epidemiology Science Center are financed by a grant from the Danish National Research Foundation.

We are indebted to support from several trade union officials - in particular Ernst Bliesmann, Peter Olesen, Rigmor Laulund, and Niels Nedergaard. The $430 \mathrm{cou}-$ ples are acknowledged for their enthusiasm in making this study possible, and the technicians from the laboratories are greatly acknowledged for performing the semen analyses.

\section{References}

1. Karasek R, Theorell T. Healthy work: stress, productivity, and the reconstruction of working life. New York (NY): BasicBooks, 1990.

2. Brandt LP, Nielsen CV. Job stress and adverse outcome of pregnancy: a causal link or recall bias? Am J Epidemiol 1992:135:302-11.

3. Fenster L, Schaefer C, Mathur A, Hiatt RA, Pieper C, Hubbard $\mathrm{AE}$, et al. Psychologic stress in the workplace and spon- taneous abortion. Am J Epidemiol 1995;142:1176-83.

4. Homer CJ, James SA, Siegel E. Work-related psychosocial stress and risk of preterm, low birthweight delivery. Am J Public Health 1990;80:173-7.

5. Henriksen TB, Hedegaard M, Secher NJ. The relation between psychosocial job strain, and preterm delivery and low birthweight for gestational age. Int $J$ Epidemiol 1994;23:764-74.

6. Harlow SD, Matanoski GM. The association between weight, physical activity, and stress and variation in the length of the menstrual cycle. Am J Epidemiol 1991;133:38 - 49.

7. Johnson EO, Kamilaris TC, Chrousos GP, Gold PW. Mechanisms of stress: a dynamic overview of hormonal and behavioral homeostasis. Neurosci Biobehav Rev 1992;16:115-30.

8. Meyerhoff JL, Oleshansky MA, Kalogeras KT, Mougey EH, Chrousos GP, Granger LG. Neuroendocrine responses to emotional stress: possible interactions between circulating factors and anterior pituitary hormone release. Adv Exp Med Biol 1990;274:91-111.

9. Schenker JG, Meirow D, Schenker E. Stress and human reproduction. Eur J Obstet Gynecol Reprod Biol 1992;45:1-8.

10. Chatterton RT. The role of stress in female reproduction: animal and human considerations. Int J Fertil 1990;35:8-13.

11. Seibel MM. Emotional aspects of infertility. Fertil Steril 1982;37:137-45.

12. Bonde JPE, Hjollund NHI, Jensen TK, Ernst E, Kolstad HA, Henriksen TB, et al. A follow-up study of environmental and biologic determinants of fertility among 430 Danish first pregnancy planners: design and methods. Reprod Toxicol 1998;12:19-27.

13. Karasek R. Job content questionnaire and user's guide, Rev 1.1. Los Angeles (CA): University of South California, Department of Industrial Medicine and System Engineering, 1985.

14. Hosmer DWJ, Lemeshow S. Applied logistic regression. New York (NY): John Wiley \& Sons Inc, 1989.

15. SAS Institute Inc. SAS/STAT user's guide, version 6, volume 2. 4th ed. Cary (NC): SAS Institute Inc, 1989.

16. Weinberg CR, Baird DD, Wilcox AJ. Sources of bias in studies of time to pregnancy. Stat Med 1994;13:671—81.

17. Kristensen TS. The demand-control-support model; methodological challenges for future research. Stress Med 1995;11:17-26. 


\section{Appendix}

Characteristics of the population at the time of enrollment and their distributions of the median scores for job control and job demands ${ }^{a}$

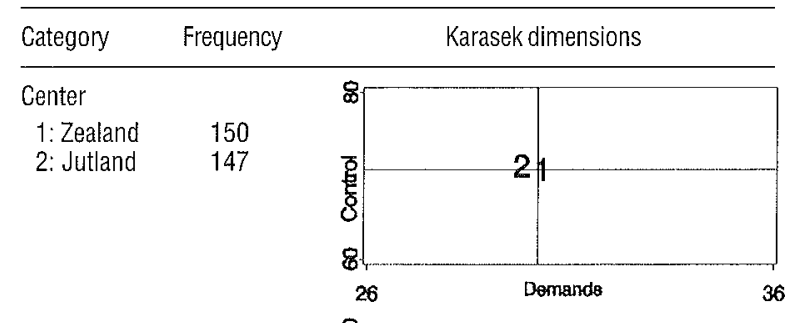

$$
\begin{array}{lr}
\text { Age (year) } \\
\begin{array}{lr}
1: \leq 24 & \\
2: 20-24 & 95 \\
3: \geq 25 & 182 \\
& 20
\end{array}
\end{array}
$$

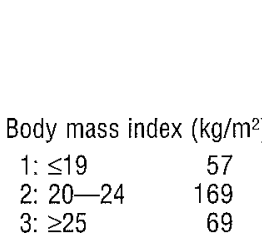

Mean menstrual cycle length $(d)$

$\begin{array}{lr}\text { 1: } \leq 26 & 38 \\ 2: 27-29 & 112 \\ 3: 30-32 & 70 \\ \text { 4: } \geq 33 & 72\end{array}$

$4: \geq 33$

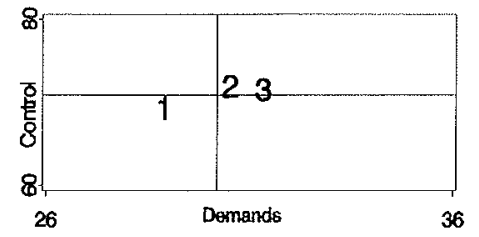

Smoking (cigarettes/d)

1: 0

2: $1-9$
$3: 10-19$

4: $\geq 20$

203
33
51
10

Alcohol consumption (drinks/week)

$\begin{array}{lr}1: 0 & 73 \\ 2: 1-4 & 119 \\ 3: 5-9 & 67 \\ 4: \geq 10 & 38\end{array}$
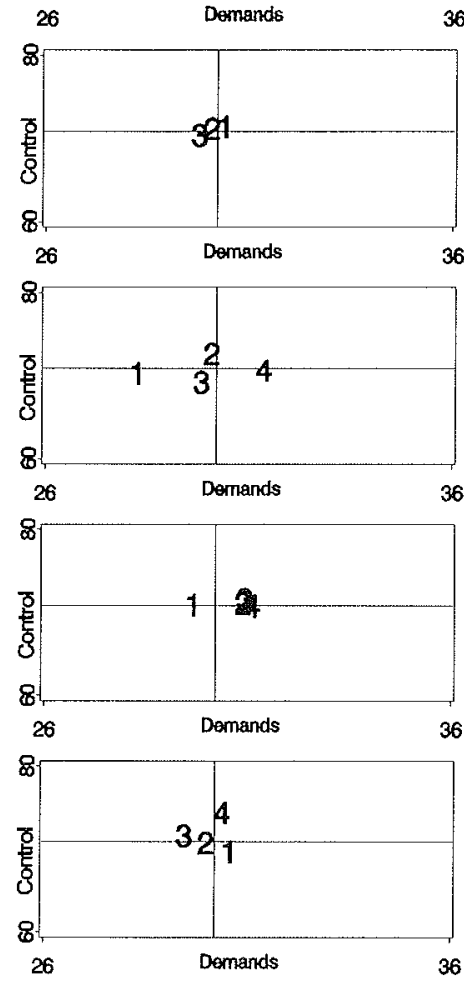

Caffein intake (mg caffein/d)

1: $0-149$

2: $150-299$

3: $300-699 \quad 119$

4: $\geq 700$ 28

Gender of index person

1: female

152

2: male

\begin{tabular}{|c|c|c|}
\hline Category & Frequency & Karasek dimensions \\
\hline \multicolumn{3}{|l|}{ Education } \\
\hline $1: 9-10$ grade & le 11 & \\
\hline 2: high school & 5 & \\
\hline 3: vodational & 144 & \\
\hline $\begin{array}{l}\text { 4: further } \\
\text { education }\end{array}$ & 137 & \\
\hline
\end{tabular}

145

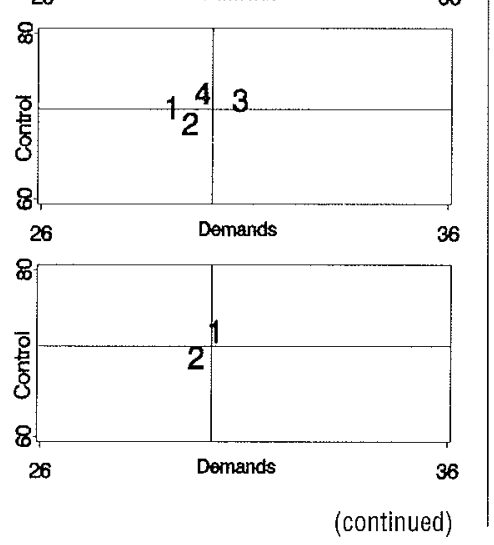

Trade

1: production

industry

$(11-39) \quad 35$

2: wholesale and retail $(20-24) 41$

3: commercial ser-

vice $(71-83) 57$

4: education and research (93.1) 12

5: health institu-

tions (93.3) 102

6 : social wel-

fare (93.4) 33

7: other (99) 17

Source of recruitment

(trade union)

1: metal

2: office

3: nurses

4: day care

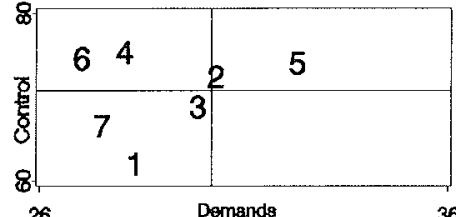

Colleagues (N)

$1: \leq 9$

2: $10-19$

$3: \geq 20$
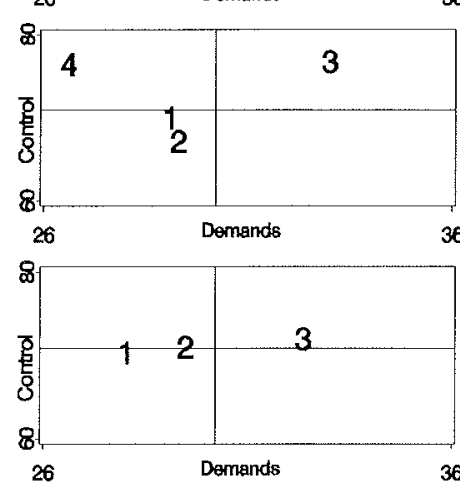

Subordinates (N)

1: none 253

2: $1-5$

3:10-19

$4: \geq 6$

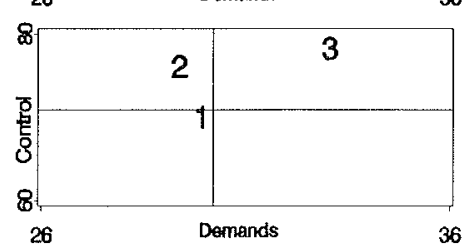

Regular work hours

1: yes

184

2: no

112

Workshift

1: only day time 216

2: evening and

day time

3: night work

$(\geq 25 \%)$

39

41
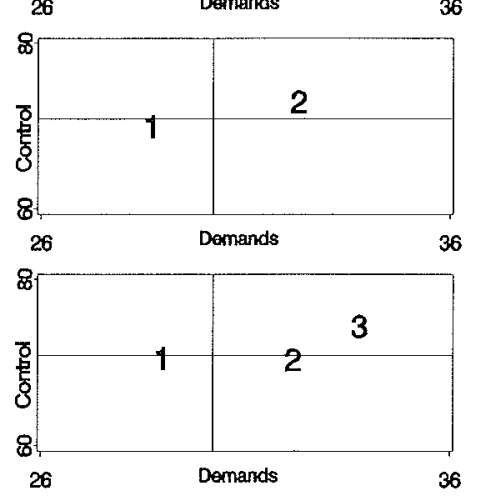

(continued) 


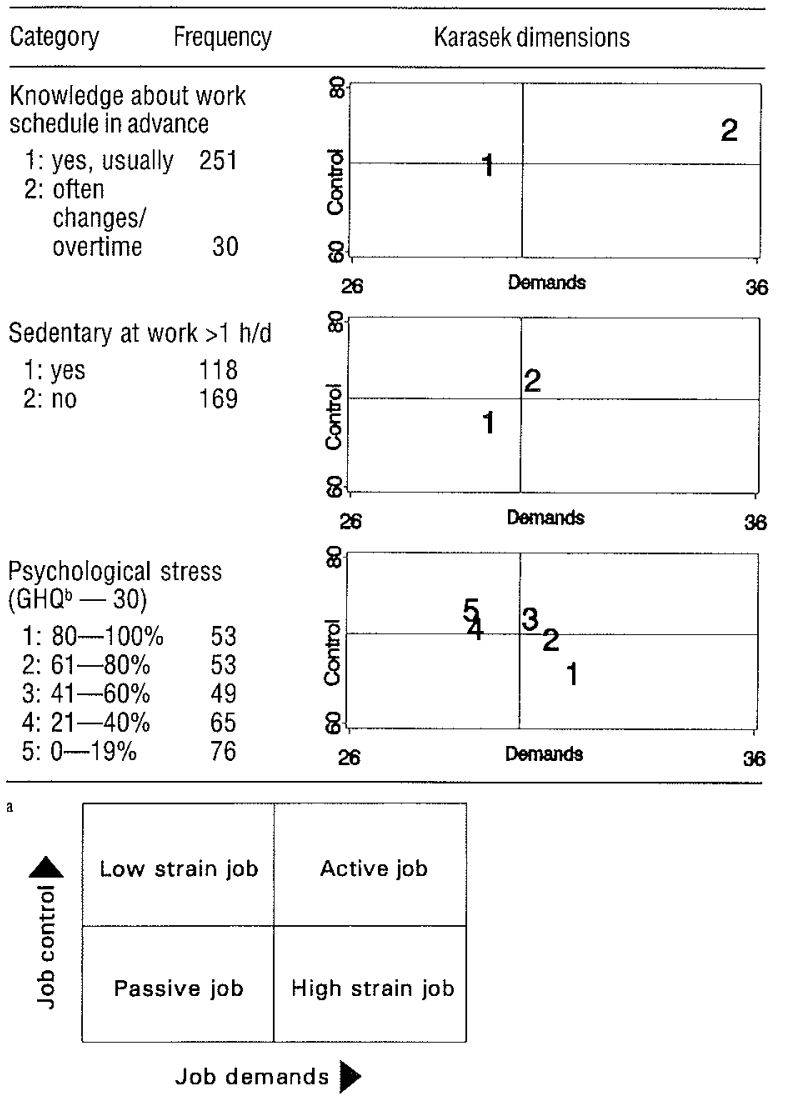

${ }^{\circ} \mathrm{GHQ}=$ General Health Questionnaire.

Received for publication: 6 February 1998 